Article

\title{
Optimization Design of Actuator Parameters with Stepless Capacity Control System Considering the Effect of Backflow Clearance
}

\author{
Jinjie Zhang ${ }^{1, *}$, Chao Zhou ${ }^{2}$, Zhinong Jiang ${ }^{3}$, Yao Wang ${ }^{2}$ and Xu Sun ${ }^{2}$ \\ 1 State Key Laboratory of Compressor Technology (Anhui Provincial Laboratory of Compressor Technology) \\ Hefei 23031, China \\ 2 Beijing Key Laboratory of Health Monitoring Control and Fault Self-Recovery for High-end Machinery \\ Beijing University of Chemical Technology; Beijing 100029, China; 2016400127@mail.buct.edu.cn (C.Z.); \\ 2019730009@mail.buct.edu.cn (Y.W.); 2019400154@mail.buct.edu.cn (X.S.) \\ 3 College of Materials Science and Engineering, Beijing University of Chemical Technology, Beijing 100029, \\ China; jiangzhinong@263.net \\ * Correspondence: 2016500030@mail.buct.edu.cn
}

Received: 8 February 2020; Accepted: 9 April 2020; Published: 14 April 2020

\begin{abstract}
The actuator is the key to the stepless capacity control system of a reciprocating compressor. The coupling effect between the actuator and the reciprocating compressor was not considered in the traditional design, and the large design margin led to low system reliability, high cost and low safety. In this paper, a reciprocating compressor and actuator were taken as research objects. The backflow clearance of the suction valve was simulated by CFD (computational fluid dynamics), The relationship between backflow clearance and resultant gas force of the valve plate was discussed. By building a mathematical model of actuators considering backflow clearance and impact rebound, the relationship between the parameters of actuators was studied. Based on the mathematical model and CFD analysis, the hydraulic force and spring stiffness were taken as the design variables, the impact velocity of ejection or withdrawal and the backflow clearance were taken as objective functions, and the actuator parameters were optimized with NSGA-II (Non-dominated Sorting Genetic Algorithm - II). The optimization results show that when the backflow clearance is $0.0065 \mathrm{~mm}$, the hydraulic force is $94.25 \mathrm{~N}$, and the spring stiffness is $11,575.84 \mathrm{~N} / \mathrm{m}$, the objective functions are optimized, the parameters are significantly improved, and a good effect is achieved on the experimental table of a $2 \mathrm{D}$ reciprocating compressor.
\end{abstract}

Keywords: reciprocating compressor; stepless capacity control system; actuator; backflow clearance; CFD; NSGA-II

\section{Introduction}

A reciprocating compressor is widely used in the petroleum, chemical, metallurgy, national defense and other industries, and is an indispensable equipment for compression and gas transmission [1]. Due to the variation of production demands, the exhaust volume of a compressor needs to be adjusted to meet the technological requirements [2]. The capacity control methods of a compressor are various, and there are a lot of descriptions in references [3,4]. A stepless capacity control system has been widely applied in production practice due to its wide range of regulation, significant energy-saving effect and the realization of stepless regulation [5,6].

A stepless capacity control system involves hydraulic, mechanical control methods and other fields. Many researchers at home and abroad had made further studies on its performance, influence and control methods. Tang et al. studied the thermodynamic performance of a reciprocating compressor 
under a stepless capacity control condition, and concluded that the suction valve flow resistance decreased during the suction process and the pressure fluctuation in the cylinder decreased, but the backflow resistance increased during the backflow process, which had a negative impact on the power and efficiency of the compressor [7]. Li et al. designed a stepless capacity control system for a reciprocating compressor based on a new type of rotary control valve [8]. Wang et al. established an improved mathematical model of a reciprocating compressor under the capacity control condition, and analyzed the influence of the hydraulic force, stroke and speed of the actuator on the gas pressure of the cylinder [9]. Liu et al. established a mathematical model including the compressor, actuator and hydraulic system, and analyzed the influence of oil pressure, holding time, hydraulic cylinder diameter and reset spring stiffness on the compressor [10]. Cao et al. used computational fluid dynamics (CFD) software to analyze the internal flow of the hydraulic distributor, and optimized the structure of the distributor through the simulation results [11]. Hong et al. established a thermodynamic mathematical model of a reciprocating compressor under stepless capacity control conditions, and designed a stepless capacity control system including a hydraulic distributor [12]. Wang et al. studied the dynamic characteristics of the valve of a reciprocating compressor with capacity control system, and optimized the valve spring and the reset spring of unloader [13]. Jin et al. considered the dynamic thermal cycle of the valve and established the dynamic model of the valve of a reciprocating compressor under a capacity control system based on the l-k actual gas state equation [14]. Wang et al. conducted a simulation study on different capacity control methods to compare the compressor shaft power and mechanical efficiency, which was conducive to the optimal design of capacity control system [15]. Xu et al. studied the dynamic characteristics of a reciprocating compressor with capacity control system. The connecting rod force and normal force were both within the range. Moreover, it had little influence on the uneven axial velocity of the compressor, and the flywheel moment could completely satisfy the capacity control condition, and the capacity control system has little influence on the dynamic performance of the compressor [16]. Zhao et al. studied the influence of spring stiffness and hydraulic pressure on the characteristics of the actuator through experiments, and proposed that dynamic response performance and working life should be considered in the design of the actuator [17]. Tang et al. studied the dynamic characteristics of the suction valve in the stepless capacity control system of a reciprocating compressor. The stepless capacity control system changed the dynamic characteristics of the suction valve, which was beneficial to prolong the life of the valve plate [18]. Although many scholars had built the model of the reciprocating compressor with the actuator, and analyzed the influence of the parameters, they had not considered the effect of the valve plate on the parameter design of the actuator. On the other hand, the simple design of a single target was carried out, so all parameters could not be optimized at the same time. The optimization of a single target might lead to the deterioration of other parameters.

At present, the research on the cylinder flow field of a reciprocating compressor was mainly based on two-dimensional or three-dimensional numerical simulation. He et al. constructed the three-dimensional fluid structure interaction model of a refrigerator compressor, which provides a reference for the testing and optimization of a compressor [19]. Jonatas et al. studied the heat transfer phenomenon inside a reciprocating compressor by constructing a three-dimensional discrete model of the solid and fluid [20]. Wu et al. built a CFD model of the reciprocating compressor with stepless capacity control system, and obtained the gas pressure field distribution of the cylinder and valve during the working process of the reciprocating compressor [21]. Xiao et al. used dynamic grid technology to simulate the working process of a reciprocating compressor cylinder and analyzed the influence of related parameters on pressure loss [22]. Fluent is a widely used CFD software with a wide range of applications, covering basically all fluid-related fields, high stability and efficiency. It is an extremely effective method to use Fluent to simulate the cylinder pressure of a reciprocating compressor.

In this paper, a mathematical model of the actuator is constructed, including the parameters of hydraulic force, resultant gas force of valve plate, spring force, and the cylinder pressure. The motion equation of the actuator under the condition of capacity control is obtained. Then, a three-dimensional 
model of the compressor cylinder and valve is built through CFD to simulate the cylinder pressure under different backflow clearance, and the relationship between the backflow clearance and the resultant gas force of the valve plate is obtained. Finally, with the design variables of the hydraulic force and spring stiffness, and the objective functions of ejection or withdrawal impact velocity and backflow clearance, the parameters of the actuator were optimized with the NSGA-II (Non-dominated Sorting Genetic Algorithm - II). The multi-objective optimization design improves the actuator parameters of the stepless capacity control system of reciprocating compressor and improves the system security and reliability.

\section{Mathematical Model of Stepless Capacity Control System}

\subsection{Mathematical Model of Actuator}

A stepless capacity control system mainly includes hydraulic system, actuator, control system. The composition of the system is shown in Figure 1. The compressor transmits the pressure signal to the DCS (Distributed Control System) system. The DCS system calculates the load signal according to the pressure signal and transmits the load signal to the intelligent controller. The intelligent controller outputs the electric signal to the solenoid valve according to the load signal and the speed signal. The hydraulic force provided by the hydraulic system drives the actuator to control the opening and closing time of the suction valve, realizing the stepless regulation of the capacity.

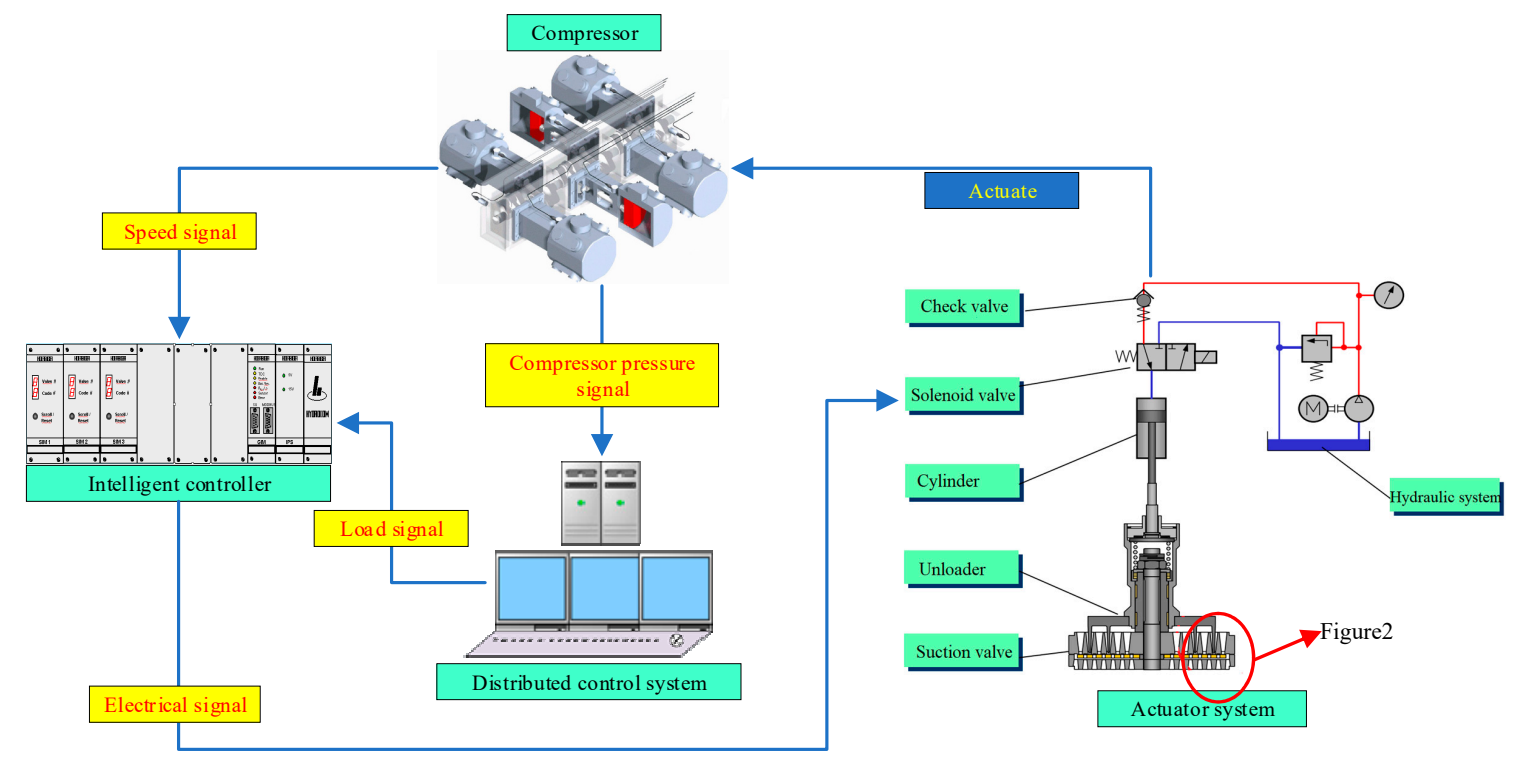

Figure 1. Composition of stepless capacity control system.

The actuator mainly includes a hydraulic cylinder, unloader and suction valve. As can be seen from Figure 2, status1 is the initial installation state. Since the actuator is not driven by hydraulic pressure, the spring force makes the actuator at the upper limit, and the suction valve is in the closed state. Status2 is the opening process of the suction valve plate. After the suction process of the compressor begins, the valve plate opens automatically. The actuator is still not driven by the hydraulic pressure and is at the upper limit. Status 3 is the opening process of the actuator. The actuator is driven by hydraulic pressure to overcome the spring force and air force, and move downward. Status 4 is the backflow process. Since the suction valve plate is forced to open, the gas reflux, when the hydraulic force is small, in the backflow process. During the backflow phase, the lower surface of the valve plate has a clearance of $h_{2}$ from the valve lift limiter. Status 5 is the closing process of the actuator and the suction valve. When the capacity meets the technical requirements, the hydraulic force does not work, and the valve plate and the actuator withdraw at the same time. 

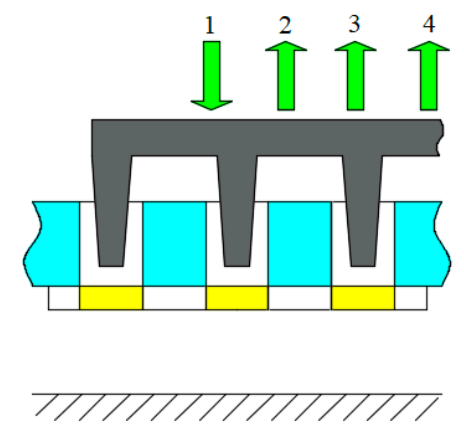

Status 1: initial installation

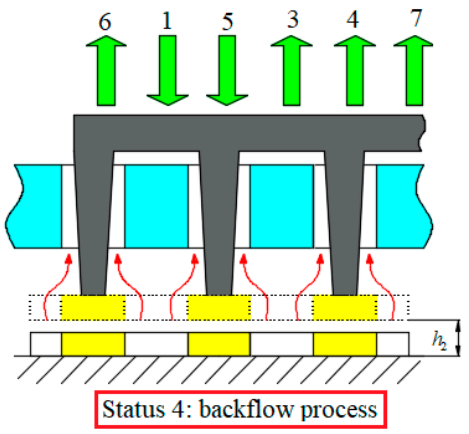

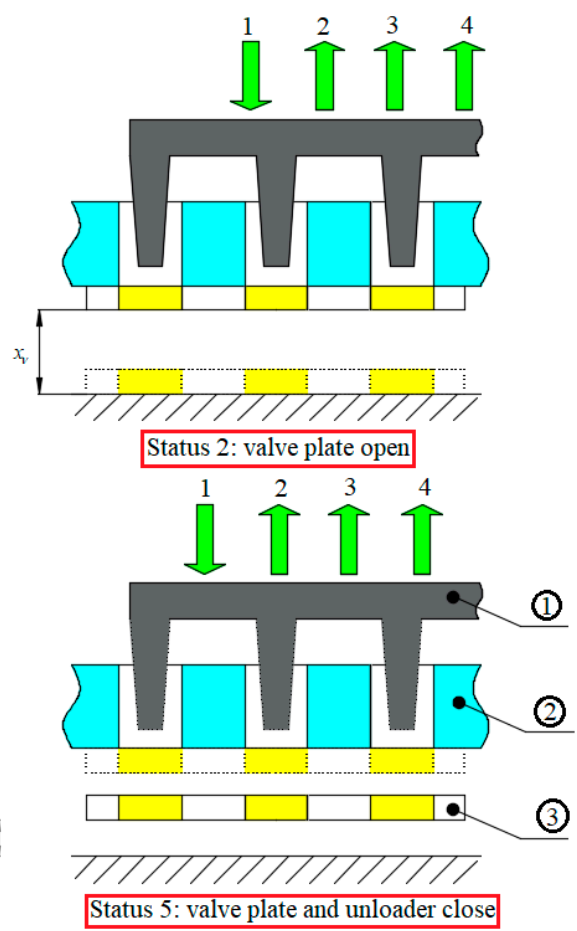

Status 5: valve plate and unloader close

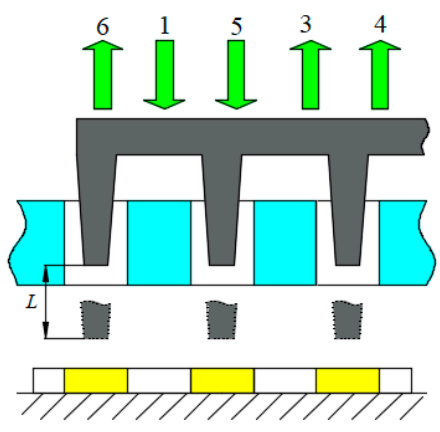

Status 3: unloader open

1 Gravity of the unloader

2 Preload of spring

3 Friction

(1) Unloader

4 Gas force of chamber (2) Valve plate

5 Hydraulic force (3) Valve seat

6 Maximum spring force

7 Gas resultant force of valve plate

Figure 2. Displacement diagram of valve plate and actuator.

During the process of ejection, the actuator is subjected to hydraulic force, spring force, gas force, friction force, etc. The rebound during the impact of the actuator is taken into consideration. The rebound coefficient $\gamma$ is measured by experiment. The differential equations of ejection and withdrawal of the actuator are shown in Equation (1):

$$
m \frac{\mathrm{d}^{2} x}{\mathrm{~d} t^{2}}=\left\{\begin{array}{l}
P_{h}-F_{i}+m g \cos \alpha-f-F_{s}, \text { status } 3-\text { ejection } \\
P_{h}-F_{i}+m g \cos \alpha+f-F_{s}, \text { status } 3-\text { rebound } \\
F_{s}+F_{i}+F_{c y}-f-m g \cos \alpha, \text { status } 5-\text { withdrawal } \\
F_{s}+F_{i}+F_{c y}+f-m g \cos \alpha, \text { status } 5-\text { rebound }
\end{array}\right.
$$

where, $m$ represents the quality of the moving parts of the actuator, $x$ represents the actuator displacement, $P_{h}$ represents hydraulic force, $F_{i}$ represents gas force of suction chamber, $\alpha$ represents mounting angle of the unloader, $f$ represents total friction of actuator, $F_{s}$ represents spring force of unloader, $F_{c y}$ represents The resultant gas force of the valve plate is related to the backflow clearance $h_{2}$, in the process of backflow, the suction valve plate is in contact with the actuator claw due to the increased pressure in the cylinder, and the valve plate exerts a force on the actuator, that is $F_{c y}$.

The hydraulic force and spring force in Equation (1), initial conditions and constraint conditions are as follows:

(1) Hydraulic force $P_{h}$ :

$$
P_{h}=p_{1} A_{\text {unloader }}, \alpha_{2} \leq \theta \leq \alpha_{3}
$$

where, $p_{1}$ represents the oil pressure in the ejection process of the actuator, $A_{\text {unloader }}$ represents the sectional area of the hydraulic cylinder plunger, $\alpha_{2}$ represents the start angle of the ejection, $\alpha_{3}$ represents the end angle of the ejection.

(2) Spring force $F_{s}$ :

$$
F_{S}=\left\{\begin{array}{l}
k_{\text {unloader }}\left(x_{0}+x\right), \alpha_{2} \leq \theta \leq \alpha_{3} \\
k_{\text {unloader }}\left(x_{\max }-x\right), \alpha_{5} \leq \theta \leq \alpha_{6}
\end{array}\right.
$$


where, $k_{\text {unloader }}$ represents the spring stiffness of the actuator, $x_{0}$ represents the precompression of the spring, $x_{\max }$ represents the maximum compression of the spring, $\alpha_{5}$ represents the start angle of withdraws, and $\alpha_{6}$ represents the end angle of withdraws.

(3) The initial condition of ejection or withdraw:

$$
\begin{aligned}
& \left\{\begin{array}{l}
v(0)=0 ; \\
x(0)=0 ;
\end{array}\right. \text { status3-ejection } \\
& \left\{\begin{array}{l}
v(0)=0 ; \\
x(0)=h_{2} ;
\end{array}\right. \text { status5 - withdrawal } \\
& \left\{\begin{array}{l}
v(0)=\gamma v_{1} ; \\
x(0)=L_{u n l o a d e r} ;
\end{array} ;\right. \text { status3 - rebound } \\
& \left\{\begin{array}{l}
v(0)=\gamma v_{2} ; \\
x(0)=L_{\text {unloader } ;} ; \text { status } 5-\text { rebound }
\end{array}\right.
\end{aligned}
$$

where, due to the existence of backflow clearance in the backflow process, the initial displacement of the retraction process is $h_{2}$, and $L_{\text {unloader }}$ represents the actuator stroke.

(4) Constraint condition

$$
\left\{\begin{array}{l}
h_{2} \leq\left(h_{2}\right)_{\max }, \alpha_{2} \leq \theta \leq \alpha_{3} \\
k_{\text {unloader }} x_{0}+F_{i}+F_{c y}-m g \cos \alpha-f \geq 0, \alpha_{5} \leq \theta \leq \alpha_{6}
\end{array}\right.
$$

Constraint condition 1 is to ensure that the clearance at the balance position of the actuator in the process of ejection and backflow is less than or equal to the maximum allowable backflow clearance. Constraint condition 2 requires that the upper limit should be withdrawn so that the valve can be closed normally to ensure the adjustment effect.

The motion equation of ejection and withdrawal can be obtained from the differential equation and constraint conditions of the actuator:

$$
x=\left\{\begin{array}{l}
\text { ejection }\left\{\begin{array}{l}
C_{1}\left(1-\cos \sqrt{\frac{k}{m}} t\right), \alpha_{2} \leq \theta \leq \alpha_{3} \\
\left(L_{\text {unloader }}-C_{2}\right) \cos \sqrt{\frac{k}{m}} t+\frac{\gamma v_{1}}{\sqrt{\frac{k_{\text {unloader }}}{m}}}+C_{2}, \text { First rebound }
\end{array}\right. \\
\text { withdrawl }\left\{\begin{array}{l}
\left(h_{2}-C_{3}\right) \cos \sqrt{\frac{k}{m}} t+C_{3}, \alpha_{5} \leq \theta \leq \alpha_{6} \\
\left(L_{\text {unloader }}-C_{4}\right) \cos \sqrt{\frac{k}{m}} t+\frac{\gamma v_{2}}{\sqrt{\frac{k_{\text {unloader }}}{m}}}+C_{4}, \text { First rebound }
\end{array}\right.
\end{array}\right.
$$

where,

$$
\begin{gathered}
C_{1}=\frac{P_{h}-F_{i}+m g \cos \alpha-f-k_{\text {unloader }} x_{0}}{k_{\text {unloader }}} \\
C_{2}=\frac{P_{h}-F_{i}+m g \cos \alpha+f-k_{\text {unloader }} x_{0}}{k_{\text {unloader }}} \\
C_{3}=\frac{k_{\text {unloader }} x_{\text {max }}+F_{i}+F_{c y}-f-m g \cos \alpha}{k_{\text {unloader }}} \\
C_{4}=\frac{k_{\text {unloader }} x_{\text {max }}+F_{i}+F_{c y}+f-m g \cos \alpha}{k_{\text {unloader }}}
\end{gathered}
$$

\subsection{Computational Fluid Dynamics (CFD) Model of Reciprocating Compressor}

In order to study the relationship between the backflow clearance and the gas resultant force of the suction valve, the CFD three-dimensional model is an effective and important method to study the change law of gas pressure. The CFD model including suction valve, exhaust valve, cylinder and 
piston is built to set different backflow clearances and obtain corresponding curves, which provided the theoretical basis for the design of actuator parameters.

\subsubsection{Flow Control Equations}

Any flow problem is governed by the three conservation laws of mass, momentum and energy. The differential equation is as follows:

$$
\begin{gathered}
\frac{\partial \rho}{\partial t}+\nabla \bullet(\rho \overrightarrow{\boldsymbol{u}})=0 \\
\frac{\partial(\rho \overrightarrow{\boldsymbol{u}})}{\partial t}+\nabla \bullet(\rho \overrightarrow{\boldsymbol{u}} \overrightarrow{\boldsymbol{u}})=\rho \overrightarrow{\boldsymbol{f}}+\nabla \bullet\left(T_{i j} \overrightarrow{\boldsymbol{e}_{i}} \overrightarrow{\boldsymbol{e}}_{j}\right) \\
\frac{\partial}{\partial t}\left[\rho\left(e+\frac{U^{2}}{2}\right)\right]+\nabla \bullet\left[\rho\left(e+\frac{U^{2}}{2}\right) \overrightarrow{\boldsymbol{u}}\right]=-\rho \overrightarrow{\boldsymbol{f}} \bullet \overrightarrow{\boldsymbol{u}}-\nabla \bullet\left(\overrightarrow{\boldsymbol{u}} \bullet T_{i j} \overrightarrow{\boldsymbol{e}_{i}} \overrightarrow{\boldsymbol{e}_{j}}\right)-\rho \dot{q}-\lambda \Delta T
\end{gathered}
$$

where, $\rho$ represents the density, $U, \vec{U}$ represents the velocity, $\overrightarrow{\mathcal{U}}$ is vector, $T_{i j} \overrightarrow{\boldsymbol{e}_{i}} \overrightarrow{\boldsymbol{e}}_{j}$ represents the surface stress tensor, $\vec{f}$ represents the body force, $\dot{q}$ represents the internal heat source, $\lambda$ represents the coefficient of thermal conductivity, and $\mathrm{T}$ represents the temperature.

In order to close the above equation, the state equation of ideal gas needs to be supplemented:

$$
P=R \rho T
$$

where, $P$ represents the pressure, $R$ represents the gas constant.

For the compressible gas under extreme conditions such as non-high temperature and high frequency sound waves, the constitutive equation is:

$$
P_{i j}=-p \delta_{i j}-2 \mu\left(S_{i j}-\frac{1}{3} S_{k k} \delta_{i j}\right)
$$

where, $-p \delta_{i j}$ represents the thermodynamic pressure, $2 \mu S_{i j}$ represents the stress deviator tensor, and $-\frac{2}{3} \mu S_{k k} \delta_{i j}$ represents theIsotropic viscous stress.

\subsubsection{Boundary Conditions and Initial Conditions}

The reciprocating compressor has many moving parts and complicated structure, and the internal flow field formation process is changeable and complicated. For the unsteady flow, a reasonable setting of initial conditions and boundary conditions is the prerequisite for obtaining feasible solutions. For the unsteady flow, a reasonable setting of initial conditions and boundary conditions is the prerequisite for obtaining feasible solutions. Boundary conditions and initial conditions are set according to the running state of the reciprocating compressor parameters. $\Omega_{1}$ is the inlet boundary to the up surface area of the suction valve, $\Omega_{2}$ is the initial clearance area, $\Omega_{3}$ is the outlet boundary to the outer surface of the piston cylinder, and the initial conditions and boundary conditions are as follows.

Unsteady flow initial field:

$$
\begin{gathered}
\left\{\begin{array}{l}
t=0: \\
U=U\left(\Omega_{1}+\Omega_{2}+\Omega_{3}, t_{0}\right) \\
P=P\left(\Omega_{1}+\Omega_{2}+\Omega_{3}, t_{0}\right) \\
T=T\left(\Omega_{1}+\Omega_{2}+\Omega_{3}, t_{0}\right)
\end{array}\right. \\
\left\{\begin{array}{l}
U\left(\Omega_{1}, t_{0}\right)=0 \\
P=P\left(\Omega_{1}, t_{0}\right)=101.325 \mathrm{kPa} \\
T=T\left(\Omega_{1}, t_{0}\right)=300 \mathrm{~K}
\end{array}\right.
\end{gathered}
$$




$$
\left\{\begin{array}{l}
U\left(\Omega_{2}+\Omega_{3}, t_{0}\right)=0 \\
P=P\left(\Omega_{2}+\Omega_{3}, t_{0}\right)=280 \mathrm{kPa} \\
T=T\left(\Omega_{2}+\Omega_{3}, t_{0}\right)=395 \mathrm{~K}
\end{array}\right.
$$

Boundary conditions:

$$
\left\{\begin{array}{l}
P\left(\Sigma_{\text {inlet }}\right)=101.325 \mathrm{kPa} \\
P\left(\Sigma_{\text {outlet }}\right)=280 \mathrm{kPa} \\
T\left(\Sigma_{\text {inlet }}\right)=300 \mathrm{~K} \\
T\left(\Sigma_{\text {outlet }}\right)=395 \mathrm{~K} \\
\quad q\left(\Sigma_{\text {else }}\right)=0
\end{array}\right.
$$

where, $\Omega$ represents the volume, $\Sigma$ represents the surface, $q$ represents the heat flux.

\subsubsection{CFD Model of Compressor Cylinder and Valve}

The test bench is a one-stage double cylinder double acting reciprocating compressor, In addition, cylinder and the valve of the cover side and shaft side are longitudinally symmetrical. In order to facilitate calculation, axisymmetric modeling is adopted. The modeling domain is the clearance volume of the cylinder on the side of the cover, one suction valve and one exhaust valve. Compressor parameters are shown in Table 1. The CFD model is shown in Figure 3.

Table 1. Compressor parameters.

\begin{tabular}{cccc}
\hline Parameter & Symbol & Unit & Value \\
\hline Rotational speed & $\mathrm{n}$ & $\mathrm{r} / \mathrm{min}$ & 300 \\
Radius of the crankshaft & $\mathrm{r}$ & $\mathrm{m}$ & 0.09 \\
connecting rod length & 1 & $\mathrm{~m}$ & 0.45 \\
Radius of the cylinder & $\mathrm{r}_{\mathrm{c}}$ & $\mathrm{m}$ & 100 \\
suction pressure & $\mathrm{p}_{\mathrm{i}}$ & $\mathrm{kPa}$ & 100 \\
Exhaust Pressure & $\mathrm{p}_{\mathrm{d}}$ & $\mathrm{kPa}$ & 200 \\
\hline
\end{tabular}
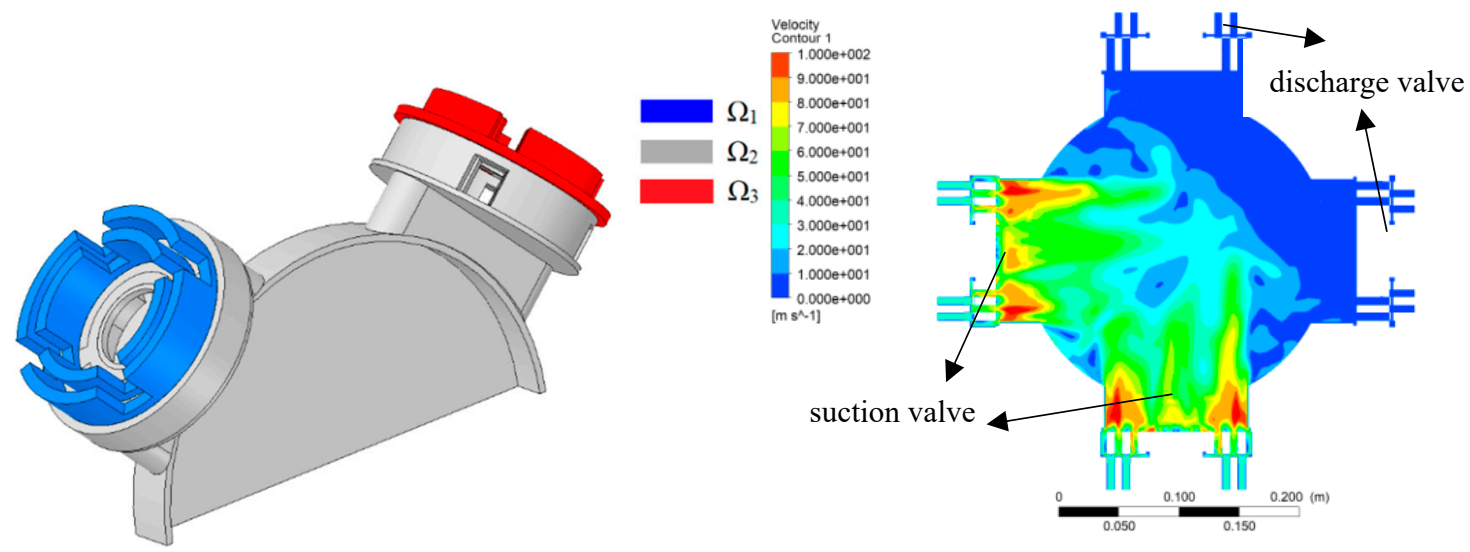

Figure 3. Outline diagram of reciprocating compressor and velocity cloud diagram during suction.

\subsubsection{Dynamic Mesh Control Equation of Valve Plate}

In the process of opening and closing or rebounding, the flow of the valve plate is caused by the movement of the boundary of the basin and the shape of the basin changes with time, so the dynamic grid model must be adopted.

(1) In the opening and closing process of valve plate, the velocity equation is:

$$
v_{n}=v_{n-1}+\frac{d^{2} h}{d t^{2}} d t
$$


where, $v_{n}, v_{n-1}$ represents the velocity of different time steps, $h$ represents the valve displacement, $d t$ represents the length of time step.

(2) During the whole working process of the valve plate, the acceleration equation is:

$$
\frac{d^{2} h}{d t^{2}}=\frac{F_{g}+F_{s}^{\prime}+m_{v} g}{m_{v}}
$$

where, $F_{g}$ represents the gas resultant force on each unit on the upper and lower surface of the valve plate, $F_{s}{ }^{\prime}$ represents the spring resultant force of valve, $m_{v}$ represents the valve quality.

(3) During the collision process, the velocity is:

$$
v_{2}^{\prime}=-C_{R} v_{1}^{\prime}
$$

where, $v_{1}^{\prime}$ represents the speed of valve plate before collision, $v_{2}^{\prime}$ represents the speed of the valve plate after collision, $C_{R}$ represents the rebound coefficient, the minus sign of the equation means the velocity is going in the opposite direction. The numerical value of the rebound coefficient is usually given by experience, For the plate valve, the coefficient is usually between 0.2 and 0.3 [13].

\section{Simulation Results and Impact Analysis}

\subsection{Analysis of Actuator}

In order to determine the rebound coefficient and verify the correctness of the mathematical model of the actuator, the parameters of the actuator on the experimental platform were taken as an example to simulate the actuator motion, and then compared with the experimental data. Table 2 is the parameters of the actuator, in which the maximum action time is the key parameter of the traditional design. The structure and performance parameters of the actuator, including hydraulic force, spring stiffness, impact velocity and rebound coefficient, are discussed.

Table 2. Actuator parameters.

\begin{tabular}{cccc}
\hline Parameter & Symbol & Unit & Value \\
\hline Mass & $m$ & $\mathrm{~kg}$ & 1.5 \\
Friction & $f$ & $\mathrm{~N}$ & 30 \\
Stroke & $x_{\max }$ & $\mathrm{m}$ & 0.0075 \\
Spring stiffness & $L$ & $\mathrm{~m}$ & 0.003 \\
Maximum action time & $x_{\max }$ & $\mathrm{N} / \mathrm{m}$ & 18,425 \\
\end{tabular}

Figure 4 shows the movement curve of the actuator with different rebound coefficients and the same oil pressure. In order to make the results repeatable, two sets of data are selected for analysis. According to the calculation results, the simulated ejection time of the actuator is faster than the experimental value. $t_{B 1}-t_{A 1}=0.0041 \mathrm{~s}, t_{D 1}-t_{C 1}=0.0042 \mathrm{~s}$, The reason is that the hydraulic pipe, valve and other resistance losses during the measurement lead to the reduction of the hydraulic force. As can be seen from Table 3, when $\gamma=-0.1 \sim-0.05$, the first rebound distance is basically consistent with the experimental value. Because the output pressure of the hydraulic system is not stable, there are errors, and the measured value has a lot of fluctuations in the balance stage. Since the ejection and withdrawal impact surfaces of the actuator are similar, the rebound coefficient of the actuator is set at -0.075 . 
Table 3. The first bounce distance of different rebound coefficients.

\begin{tabular}{ccccc}
\hline $\begin{array}{c}\text { Rebound } \\
\text { Coefficient }\end{array}$ & Experiment Value & Simulation Value & Experiment Value & Simulation Value \\
\hline-0.2 & & 0.282 & & 0.194 \\
-0.1 & 0.05 & 0.085 & 0.05 & 0.052 \\
-0.05 & & 0.044 & 0.025 \\
\hline
\end{tabular}

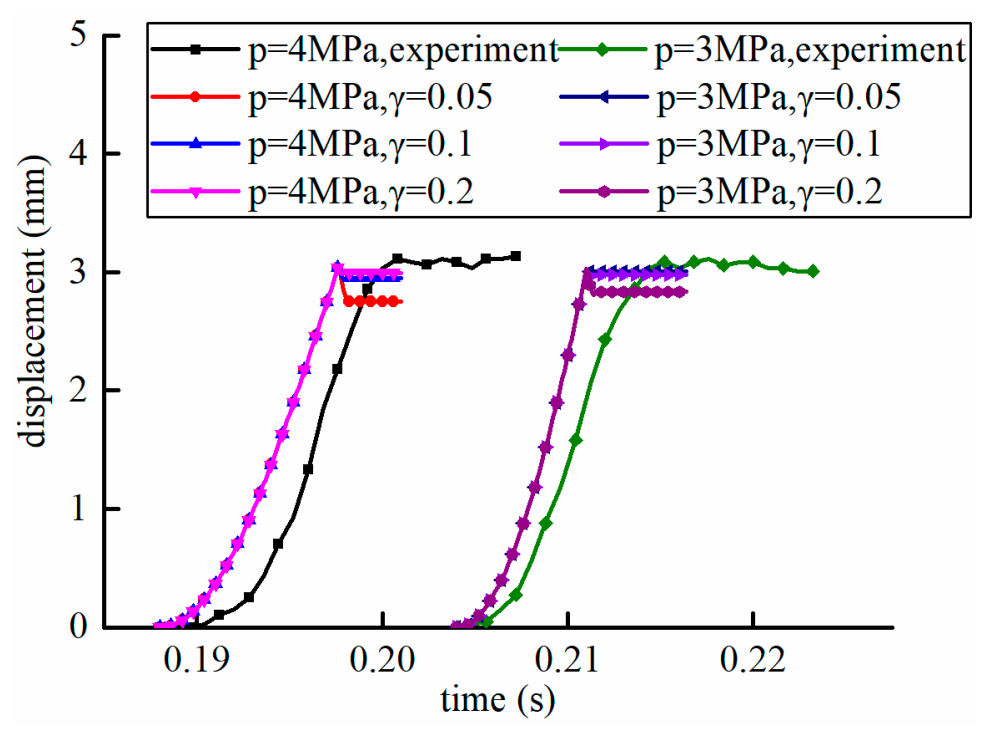

Figure 4. Movement curve of the actuator with different rebound coefficients and the same oil pressure.

Figure 5 shows the movement curve of actuator unable to overcome spring force and gas force when the hydraulic pressure is small $(\mathrm{p} 1=1.3 \mathrm{MPa})$. As can be seen from the figure, the difference between $t_{O A}$ and $t_{O B}, d_{A}-d_{C}$ and $d_{B}-d_{D}$ is small. The accuracy and feasibility of the mathematical model are verified.

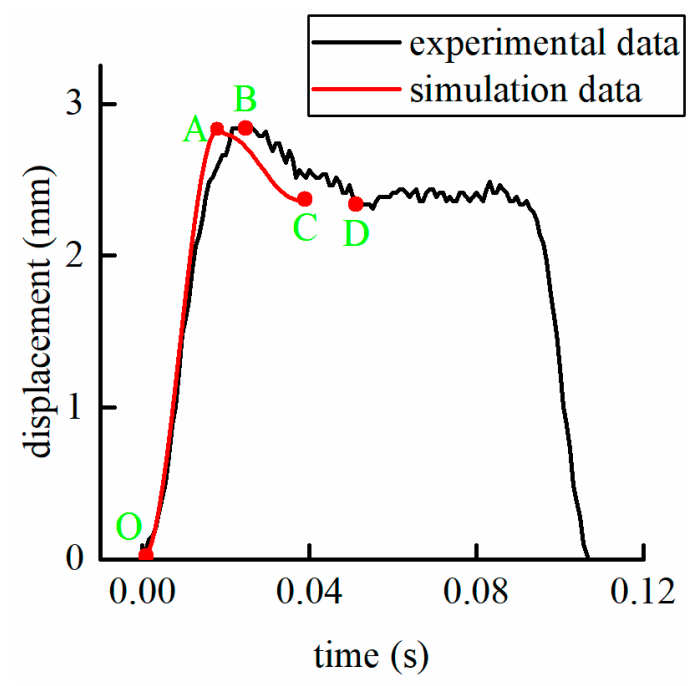

Figure 5. Movement curve of actuator with small hydraulic pressure.

For the ejection process, the hydraulic system is the driving source and the spring is the resistance element. For the withdrawal process, the hydraulic system has no output force, and the spring force releases the accumulated energy during the ejection process as the driving source. Therefore, in the ejection process, the impact velocity is positively correlated with the hydraulic force, and negatively correlated with the spring stiffness. In the withdrawal process, the impact velocity has nothing to do 
with the hydraulic force, but has a positive correlation with the spring stiffness. Since the speed after the rebound is small, the speed of the rebound is not considered. Take the derivative of Equation (5) to obtain the function of actuator speed, spring stiffness and hydraulic force:

$$
v(t)=\left\{\begin{array}{l}
C_{1} \sqrt{\frac{k_{\text {unloader }}}{m}} \sin \left(\sqrt{\frac{k_{\text {unloader }}}{m}} t\right), \alpha_{2} \leq \alpha \leq \alpha_{3} \\
\left(C_{3}-h_{2}\right) \sqrt{\frac{k_{\text {unloader }}}{m}} \sin \left(\sqrt{\frac{k_{\text {unloader }}}{m}} t\right), \alpha_{5} \leq \alpha \leq \alpha_{6}
\end{array}\right.
$$

By substituting $x(t)=L$ into Equations (5) and (19), the velocity at the upper and lower limits of the actuator can be obtained, that is, the impact velocity:

$$
v=\left\{\begin{array}{l}
C_{1} \sqrt{\frac{k_{\text {unloader }}}{m}} \sqrt{1-\left(\frac{C_{1}-L}{C_{1}}\right)^{2}}, \alpha_{2} \leq \alpha \leq \alpha_{3} \\
\left(C_{3}-h_{2}\right) \sqrt{\frac{k_{\text {unloader }}}{m}} \sqrt{1-\left(\frac{L-C_{3}}{h_{2}-C_{3}}\right)^{2}}, \alpha_{5} \leq \alpha \leq \alpha_{6}
\end{array}\right.
$$

\subsection{Relationship between Backflow Clearance and Cylinder Pressure}

In order to study the relationship between backflow clearance and pressure rise during backflow, the CFD model of the reciprocating compressor was used for simulation. To ensure that the pressure curve peaks during backflow, the valve plate is fully open. There is a peak cylinder pressure at the end of the compression process (at a certain crank angle). By modifying the udf (user defined function) of the valve plate movement, the backflow clearance of the valve plate starts from $0.25 \mathrm{~mm}$, and the interval is $0.25 \mathrm{~mm}$. When the clearance of the valve plate reaches the maximum value of $2 \mathrm{~mm}$, the actuator does not interfere with the closure of the valve plate, and the reciprocating compressor is under full load, so the simulation is stopped. The simulation results are shown in Figures 6-8.

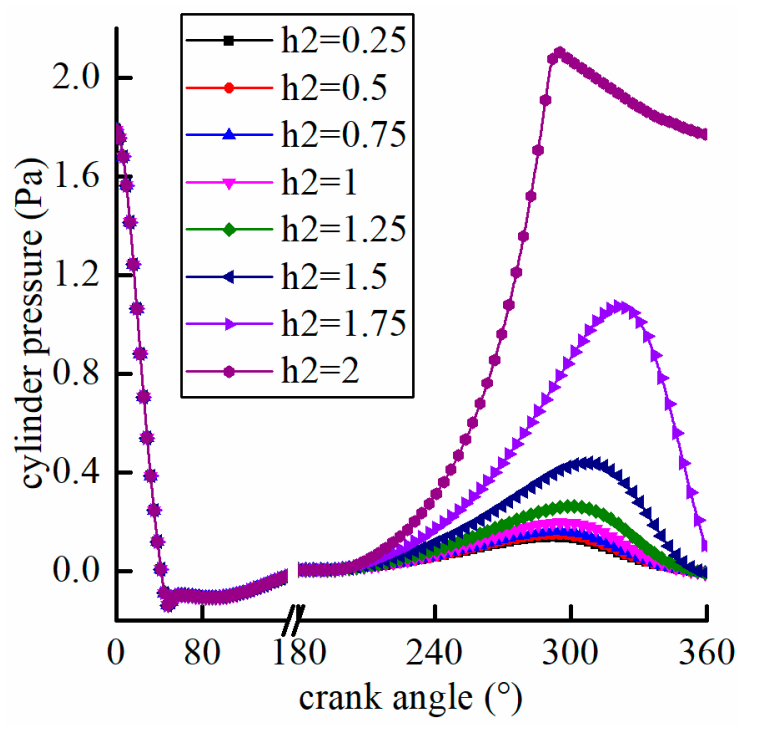

Figure 6. Cylinder pressure at different backflow clearances.

In the traditional design, the effect of the gas resultant force of valve plate on the actuator during the backflow is ignored. However, due to the machining error or small hydraulic force, the backflow clearance will inevitably exist and gradually increase, and the effect of the gas resultant force of the valve plate on the actuator will also gradually increase. As can be seen from Figure 6 and Table 4, when the clearance value is less than or equal to $1.25 \mathrm{~mm}$, the maximum gas pressure increase in the backflow process is small. By increasing the hydraulic force, the backflow clearance can be kept from increasing, and the pressure rise can be controlled so that the unit can still run stably. When the clearance reaches $1.5 \mathrm{~mm}$, the increase is close to $50 \%$. Even if the further increase of the cylinder 
pressure is controlled by increasing the hydraulic force, the backflow pressure and temperature are too high at this time, and the unit is in poor operation state. Therefore, the machine should be stopped for troubleshooting.

Table 4. Increase amplitude of cylinder pressure in different backflow clearance.

\begin{tabular}{cccccccc}
\hline Gap Value $(\mathbf{m m})$ & $\mathbf{0 . 2 5}$ & $\mathbf{0 . 5}$ & $\mathbf{0 . 7 5}$ & $\mathbf{1}$ & $\mathbf{1 . 2 5}$ & $\mathbf{1 . 5}$ & $\mathbf{1 . 7 5}$ \\
\hline Maximum pressure in backflow $(\mathrm{Pa})$ & $1.37 \times 10^{4}$ & $1.49 \times 10^{4}$ & $1.63 \times 10^{4}$ & $1.96 \times 10^{4}$ & $2.61 \times 10^{4}$ & $4.37 \times 10^{4}$ & $1.07 \times 10^{5}$ \\
Pressure increase amplitude & $13.67 \%$ & $14.88 \%$ & $16.26 \%$ & $19.58 \%$ & $26.10 \%$ & $43.72 \%$ & $107.19 \%$ \\
\hline
\end{tabular}

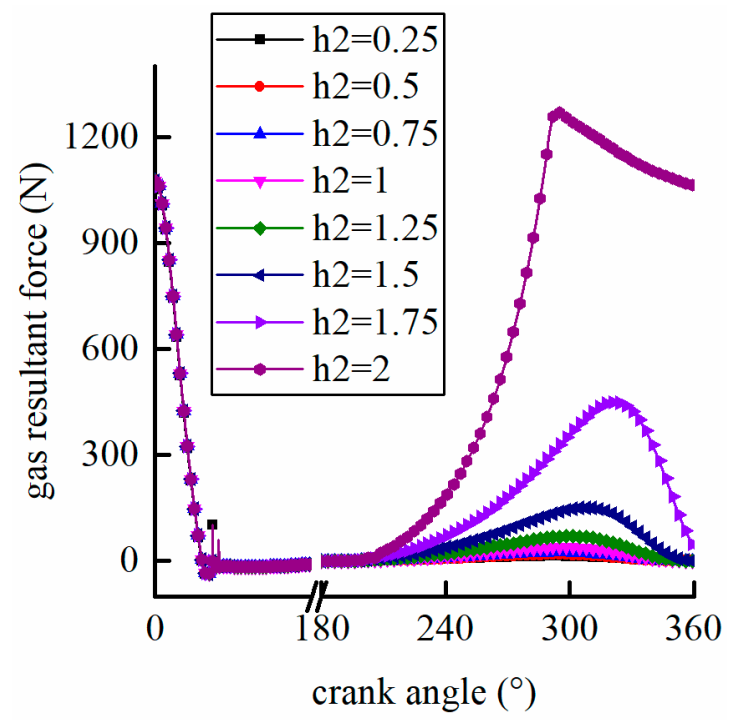

Figure 7. The gas resultant force curve of different backflow clearances.

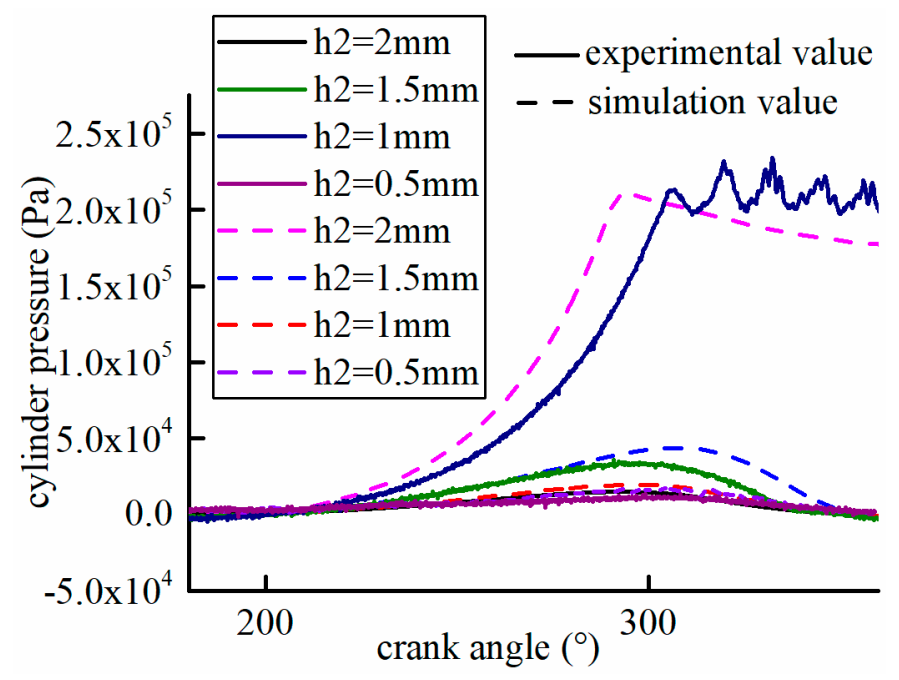

Figure 8. Experimental and simulation curves.

Figure 7 shows the gas resultant force curve of different backflow clearances, and the trend is the same as the curve of the cylinder pressure. Figure 8 shows the comparison between the experimental curve and the simulation curve. It can be seen that the error is small, which verifies the correctness of the model. Figure 9 shows the maximum gas resultant force and corresponding angle of the valve plate with different backflow clearances. When the backflow clearance is $0.25 \sim 1.25 \mathrm{~mm}$, the maximum gas resultant force and corresponding angle change little, indicating that stable operation of the capacity control system can still be achieved when the backflow is small. The relationship between backflow 
clearance and the maximum gas resultant force and the corresponding angle shows exponential growth. By fitting the exponential function, the following can be obtained:

$$
F_{c y}=9.32 e^{1.33 h_{2}}+0.01329 e^{5.822 h_{2}}
$$

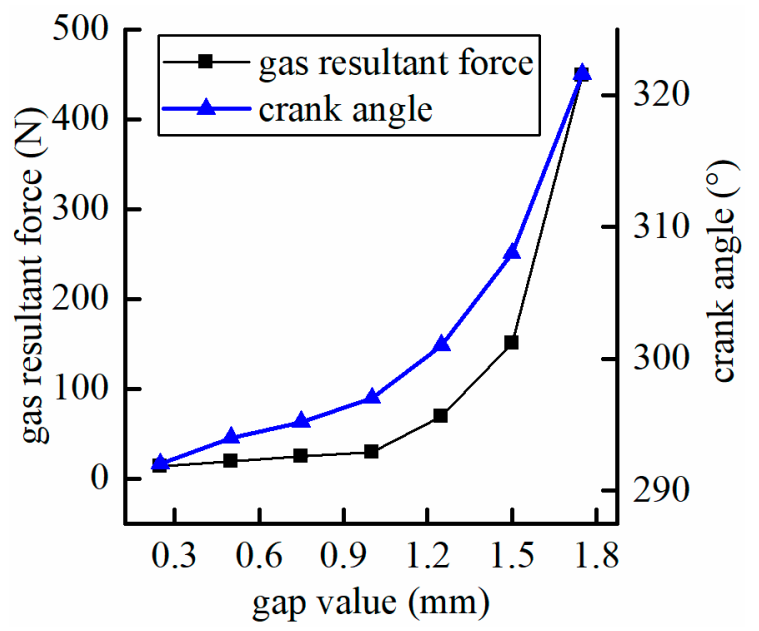

Figure 9. The relation curve of maximum gas resultant force, clearance and crank angle.

\section{Multi-Objective Optimization Model of Actuator}

As for actuator parameters, the relationship among backflow clearance, hydraulic force, spring stiffness and impact velocity is not positively correlated. The multi-objective optimization design based on backflow clearance can make the system safety and control effect better. On the premise of satisfying the control effect, the driving hydraulic force, impact velocity and spring stiffness of the actuator are minimized to meet the requirements of system safety and cost reduction.The objective function should be defined as the minimum of multiple objective functions.

$$
\begin{gathered}
\min f(X)=\left[\begin{array}{llll}
f_{1} & f_{2} & \cdots & f_{i}
\end{array}\right] \\
\text { sub } X=\left(x_{1} x_{2} \cdots x_{k}\right) \\
x_{\text {lower }} \leq x_{k} \leq x_{\text {upper }}(k=1,2 \cdots j)
\end{gathered}
$$

where, $f(X)$ represents the objective equation with respect to $X, i, j$ is the number of objective functions and decision variables, respectively, $x_{\text {lower }}$ represents the lower limit of the decision variable, $x_{\text {upper }}$ represents the upper limit of the decision variable.

\subsection{Objective Function}

(1) Impact velocity

The industrial reciprocating compressor has a fast speed, so the actuator needs to respond to the speed of the compressor to adjust the capacity. For a mechanical structure with high-frequency motion, reducing the impact velocity can increase the life of the actuator and reduce the noise. Therefore, the impact velocity of ejection and withdrawal are selected as the objective function. 


$$
f_{1}=v=\left\{\begin{array}{l}
C_{1} \sqrt{\frac{k_{\text {unloader }}}{m}} \sqrt{1-\left(\frac{C_{1}-L_{\text {unloader }}}{C_{1}}\right)^{2}}, \alpha_{2} \leq \alpha \leq \alpha_{3} \\
\left(C_{3}-h_{2}\right) \sqrt{\frac{k_{\text {unloader }}}{m}} \sqrt{1-\left(\frac{L_{\text {unloader }}-C_{3}}{h_{2}-C_{3}}\right)^{2}}, \alpha_{5} \leq \alpha \leq \alpha_{6}
\end{array}\right.
$$

(2) Hydraulic pressure and stiffness

For hydraulic systems, reducing hydraulic pressure and spring stiffness can reduce costs significantly and improve safety.

$$
\begin{gathered}
f_{2}=k_{\text {unloader }} \\
f_{3}=p_{1}
\end{gathered}
$$

(3) Backflow clearance

Reducing the hydraulic force of the capacity control system will increase the backflow clearance, increase the gas force on the valve plate, increase the force on the actuator, and then lead to the increase of the withdrawal impact speed. However, the smaller the backflow clearance, the smaller the impact on the compressor, the longer the system reliability and service life will be.

$$
f_{4}=h_{2}=x_{\max }-\frac{P_{h}-F_{i}+m g \cos \alpha-f}{k_{\text {unloader }}}
$$

\subsection{Constraint Condition}

(1) Considering the force exerted by the valve plate on the actuator in the process of backflow, and when the backflow clearance is too large, the control effect will decrease, and the exhaust temperature of the compressor will increase, which will adversely affect the efficiency and safety of the compressor. Therefore, the constraint condition of the backflow gap is:

$$
h_{2} \leq\left(h_{2}\right)_{\max }, \alpha_{2} \leq \theta \leq \alpha_{3}
$$

(2) Considering that the actuator can be withdrawn to the upper limit and maintained, the spring stiffness constraint conditions are:

$$
k_{\text {unloader }} x_{0}+F_{i}+F_{c y}-m g \cos \alpha-f \geq 0, \alpha_{5} \leq \theta \leq \alpha_{6}
$$

\subsection{Optimization Algorithm Diagram}

NSGA-II based on fast non-dominant sorting and crowding distance is a multi-objective optimization genetic algorithm. On the basis of NSGA, the elite strategy and fast non-dominant ranking strategy are added to greatly improve the shortcomings of NSGA. In this paper, the parameters of actuators are optimized by the NSGA-II. Before the optimization, the mathematical model of the actuator and the CFD model of the cylinder were established to provide the objective function and constraint conditions for the multi-objective optimization, and then the optimization calculation was carried out with the help of NSGA-II, as shown in Figure 10. First, the population is initialized within the constraints provided by the actuator and the cylinder CFD model. Then, the parent generation is formed by selection, crossover and mutation, and the offspring are formed by non-dominant sorting and fitness sorting with the help of the objective function. In this way, the calculation is completed when the number of iterations reaches the set value. 


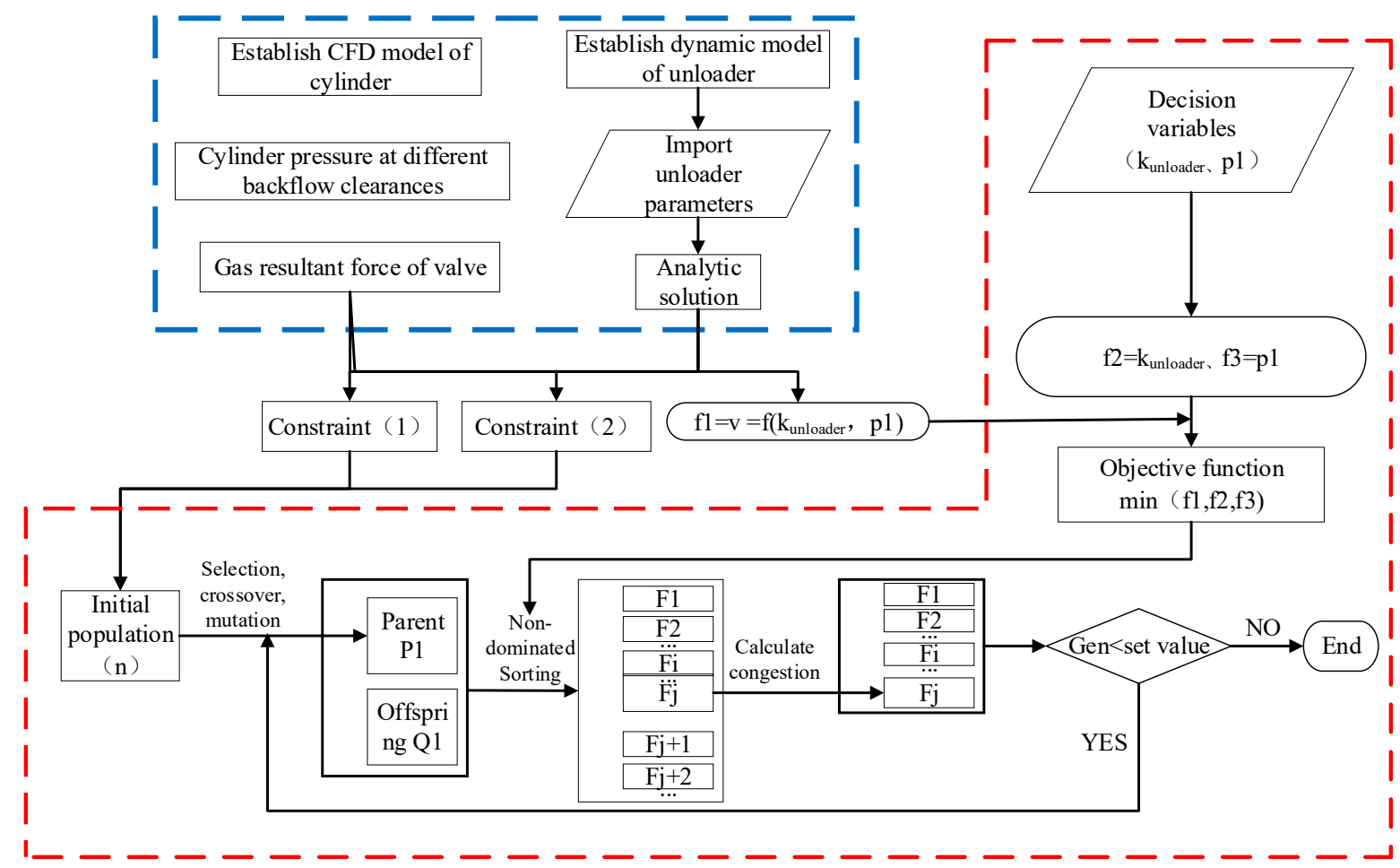

Figure 10. Optimization algorithm diagram.

\section{Optimization Results and Analysis}

The multi-objective optimization parameter settings of the non-dominant sort are shown in Table 5 . Figure 11 shows Pareto optimal solutions of spring stiffness, hydraulic pressure, impact velocity of ejection and withdrawal, and Figure 12 shows Pareto optimal solutions of spring stiffness, hydraulic pressure and backflow clearance. Figures 13 and 14 are Pareto optimal solutions of spring stiffness and hydraulic force, respectively. It can be seen from Figure 11 that the distribution trend of ejection impact velocity and withdrawal impact velocity is basically the same, but because of the constraint condition (2), the withdrawal impact velocity is greater than the ejection impact velocity. It can be seen from Figure 11 that the distribution trend of backflow clearance is opposite to the impact velocity. It can be seen from Figures 13 and 14 that the spring stiffness and hydraulic force of the design variables converge in a small range, with the spring stiffness mainly concentrated in the range of $11,550 \mathrm{~N} / \mathrm{m} \sim 11,600 \mathrm{~N} / \mathrm{m}$, and the liquid pressure mainly concentrated in the range of $86 \mathrm{~N} 102 \mathrm{~N}$.

Table 5. Parameter of NSGA-II.

\begin{tabular}{cc}
\hline Parameter & Value \\
\hline Population size & 100 \\
Generation & 1000 \\
Mutation fraction & 0.7 \\
Crossover fraction & 0.4 \\
Variation ratio & 0.02 \\
Crossover ratio & 0.02 \\
\hline
\end{tabular}

Table 6 is the design variables and objective function values of the traditional design and optimization design of Pareto optimal solutions. Design 1 represents the traditional parameters, and designs 2-4 represent the parameters after optimized design. According to the fluctuation range of hydraulic force of $86 \mathrm{~N} \sim 102 \mathrm{~N}$, three Pareto optimal solutions with hydraulic force of $87.44 \mathrm{~N}, 94.25 \mathrm{~N}$ and $101.82 \mathrm{~N}$ were uniformly selected for pre-and post-optimization comparative analysis. As can be seen from Table 6, except for the backflow clearance, all the other parameters after optimization 
have significantly decreased, with the spring stiffness decreasing by about $37 \%$, the hydraulic force decreasing by about $50.5 \%$, the ejection impact velocity decreasing by about $80.38 \%$, and the withdrawal impact velocity decreasing by about $44.23 \%$.

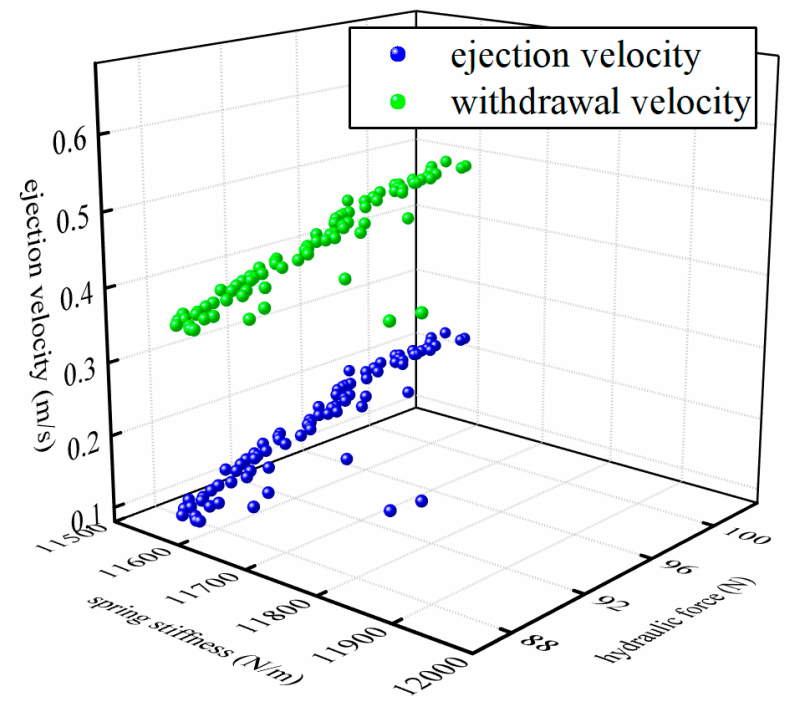

Figure 11. Pareto optimal solutions of spring stiffness, hydraulic pressure, impact velocity of ejection and withdrawal.

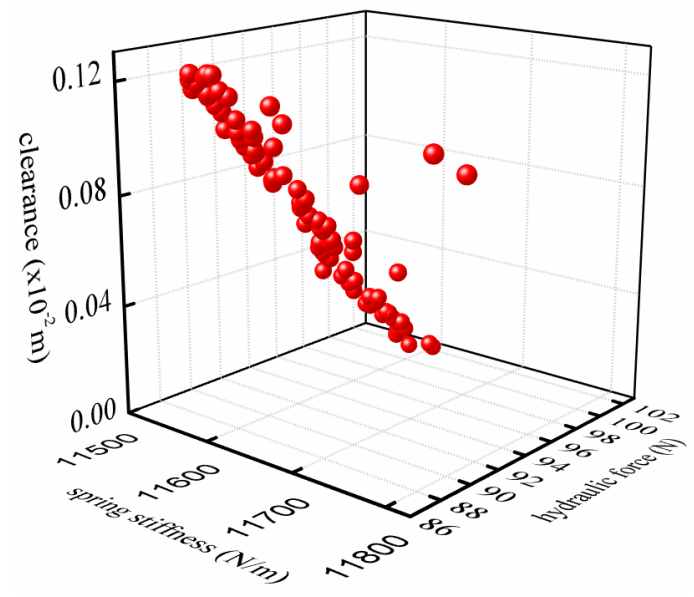

Figure 12. Pareto optimal solutions of spring stiffness, hydraulic pressure and backflow clearance.

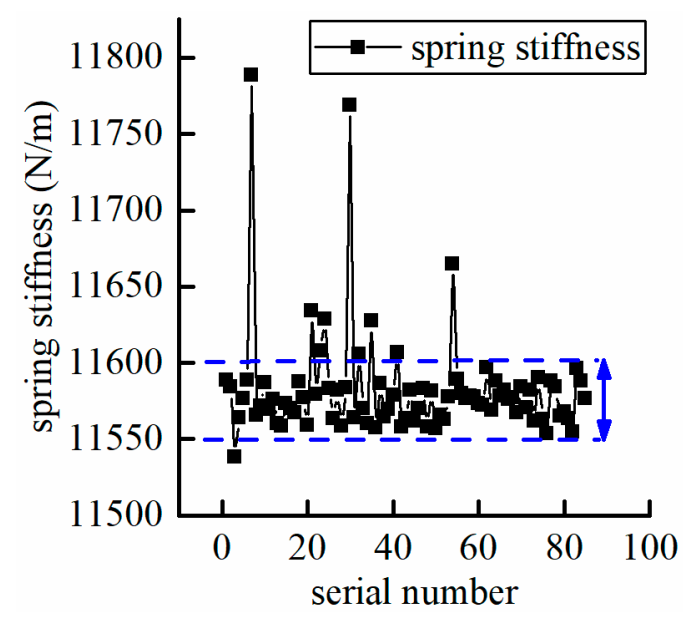

Figure 13. Pareto optimal solutions of spring stiffness. 


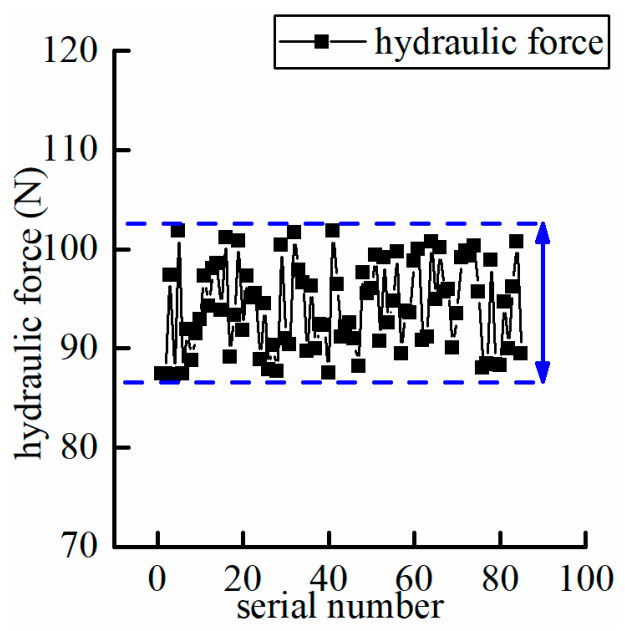

Figure 14. Pareto optimal solutions of hydraulic force.

Design 2 has a large backflow clearance and is close to the limit value, which is unfavorable to the running state of the compressor. Although the backflow clearance in design 3 is larger than that in design 4 , the difference from the limit value is large and the effect on the compressor is small. Moreover, the impact velocity and liquid pressure are both smaller than that in design 4 . Therefore, design 3 is taken as the final design parameter and the experiment is designed to verify the effect.

Table 6. The comparison of different designs.

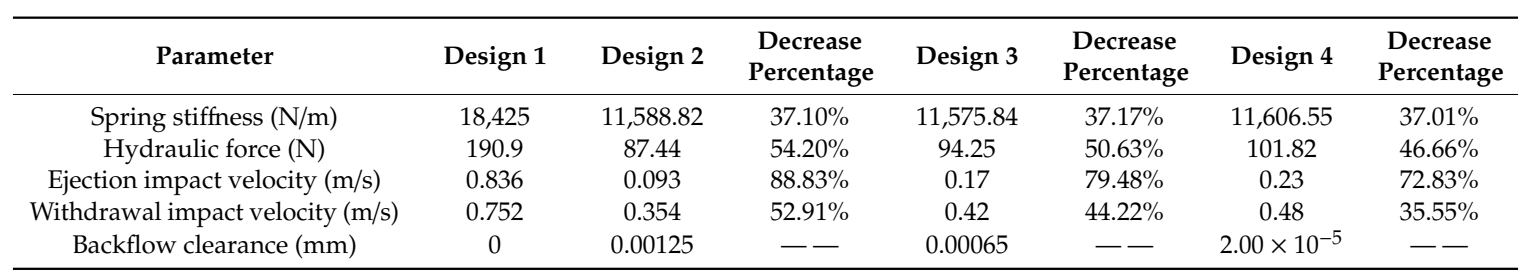

\section{Conclusions}

In this paper, the mathematical model of the actuator and the CFD model of the compressor cylinder and the valve plate are established. The relationship between different backflow clearance and the increase of cylinder pressure is studied, and puts forward an optimized design of actuator parameters considering backflow clearance, which can increase the life and performance of the stepless capacity control system of reciprocating compressor and lay a foundation for the overall optimization of the system.

(1) Firstly, the mathematical model of the actuator was established. Then, the parameters of the experimental test were taken as an example for numerical analysis. Combined with the experimental data, the rebound coefficient was determined to be -0.075 . On this basis, the motion simulation curve of the actuator was modified. Compared with the experimental motion curve, the error is small and the ejection time difference is $4 \mathrm{~ms}$, which verifies the correctness of the model. Finally, the relationship between impact velocity, spring stiffness and hydraulic pressure is analyzed. In the ejection process, the impact velocity is positively correlated with the hydraulic force, and negatively correlated with the spring stiffness. In the withdrawal process, the impact velocity has nothing to do with the hydraulic force, but has a positive correlation with the spring stiffness.

(2) The CFD model of the compressor cylinder and the valve plate was built based on the experimental platform of the capacity control system. By analyzing the data, it can be seen that the relationship between backflow clearance and the maximum gas resultant force and the corresponding angle increases exponentially. When the backflow clearance is $1.25 \mathrm{~mm}$, the pressure increases by $26.1 \%$, and the compressor can still run safely and stably. When the backflow clearance is $1.5 \mathrm{~mm}$, 
the pressure increases by $43.72 \%$, and the compressor can no longer run stably for a long time. Therefore, the $1.25 \mathrm{~mm}$ backflow clearance is taken as the maximum backflow clearance. At this point, the maximum gas resultant force of the valve plate is $69.565 \mathrm{~N}$.

(3) With spring stiffness and hydraulic force as design variables, impact velocity and backflow clearance as objective functions, multi-objective optimization was conducted based on NSGA-II. Except for the backflow clearance, all the other parameters after optimization decreased significantly, with the spring stiffness decreased by about $37 \%$, the hydraulic force decreased by about $50.5 \%$, the ejection impact velocity decreased by about $80.38 \%$, and the withdrawal impact velocity decreased by about $44.23 \%$. Finally, according to the influence of backflow clearance on the running state of the compressor, a set of design parameters of the actuator was selected from the Pareto optimal solution set.

(4) In this paper, we consider the effect of gas resultant force of the valve plate on the design of the actuator. There are many factors that affect the gas resultant force of the valve plate, such as backflow clearance, leakage, valve form and so on. The influence factors such as leakage and valve form can be carried out in subsequent works to study the law of the gas resultant force of the valve plate. The CFD model of a reciprocating compressor can be improved to obtain the temperature distribution of the cylinder under different working conditions by considering the heat conduction between fluid and wall, laying a theoretical foundation for the multi-objective optimization of the actuator design.

Author Contributions: Conceptualization, J.Z. and C.Z.; methodology, C.Z.; validation, C.Z.; validation, C.Z., Y.W. and X.S.; data curation, J.Z. and C.Z.; writing-original draft preparation, C.Z.; writing-review and editing, J.Z.; supervision, J.Z.; project administration, Z.J.; funding acquisition, J.Z. All authors have read and agreed to the published version of the manuscript.

Funding: This research was funded by National Plan on Key Basic Research and Development Plan, grant number 2016YFF0203305 and State Key Laboratory of Compressor Technology (An Hui Laboratory of Compressor Technology), grant number SKLYSJ201808.

Conflicts of Interest: The authors declare no conflict of interest. The funders had no role in the design of the study; in the collection, analyses, or interpretation of data; in the writing of the manuscript; or in the decision to publish the results.

\section{References}

1. Bloch, H.P.; Hoefner, J.J. Reciprocating Compressors Operation E Maintenance; Gulf Publishing Company: Houston, TX, USA, 1996.

2. Perreira, E.P.; Parise, J.A.R. Performance analysis of capacity control devices for heat pump reciprocating compressors. Heat Recovery Syst. CHP 1993, 13, 451-461. [CrossRef]

3. Holdack-Janssen, H.; Kruse, H. Continuous and discontinuous capacity control for high speed refrigeration compressors. Proc. Purdue Comp. Tech. Conf. 1984, 67-75.

4. Verma, J.C. Optimum utilization of capacity control devices in reciprocating compressors. Proc. Purdue Comp. Tech. Conf. 1986, 509-520.

5. Steinruck, P. Method and Apparatus for Controlling Compressor Valves in a Piston Compressor. U.S. Patent 08/851934, 1999.

6. Steinruck, P. Device and Method for Influencing the Periodic Stroke Movement of the Closing Element of a Valve. U.S. Patent 08/508 453, 1998.

7. Bin, T.; Yuanyang, Z.; Liansheng, L.; Guangbin, L.; Le, W.; Qichao, Y. Thermal performance analysis of reciprocating compressor with stepless capacity control system. Appl. Therm. Eng. 2013, 54, 380-386. [CrossRef]

8. Li, D.; Wu, H.; Gao, J. Experimental study on stepless capacity regulation for reciprocating compressor based on novel rotary control valve. Int. J. Refrig. 2013, 36, 1701-1715. [CrossRef]

9. Wang, Y.; Jiang, Z.; Zhang, J.; Zhou, C.; Liu, W. Performance analysis and optimization of reciprocating compressor with stepless capacity control system under variable load conditions. Int. J. Refrig. Rev. Int. Froid 2018, 94, 174-185. [CrossRef]

10. Liu, G.; Zhao, Y.; Tang, B.; Li, L. Dynamic performance of suction valve in stepless capacity regulation system for large-scale reciprocating compressor. Appl. Therm. Eng. 2016, 96, 167-177. [CrossRef] 
11. Cao, J.L.; Hong, W.R.; Li, Y.; He, Z.K. Study on flow field in capacity regulating actuator for reciprocating compressor. IOP Conf. Ser. Mater. Sci. Eng. 2013, 52. [CrossRef]

12. Hong, W.; Jin, J.; Wu, R.; Zhang, B. Theoretical analysis and realization of stepless capacity regulation for reciprocating compressors. Proc. Inst. Mech. Eng. Part E J. Process Mech. Eng. 2009, 223, 205-213. [CrossRef]

13. Wang, Y.; Zhang, J.; Jiang, Z.; Zhou, C.; Liu, W. Investigation on thermodynamic state and valve dynamics of reciprocating compressors with capacity regulation system and parameter optimization. Eng. Appl. Comput. Fluid Mech. 2019, 13, 923-937. [CrossRef]

14. Jin, J.; Hong, W. Valve dynamic and thermal cycle model in stepless capacity regulation for reciprocating compressor. Chin. J. Mech. Eng. 2012, 25, 1151-1160. [CrossRef]

15. Wang, L.; Liu, G.B.; Zhao, Y.Y.; Li, L.L. Performance comparison of capacity control methods for reciprocating compressors. In Proceedings of the 9th International Conference on Compressors and their Systems, London, UK, 7-9 September 2015; Volume 90.

16. $\mathrm{Xu}, \mathrm{Q}$; Hong, W. Dynamic performance of reciprocating compressor with capacity regulation system. Proc. Inst. Mech. Eng. Part E J. Process Mech. Eng. 2019, 233, 526-535. [CrossRef]

17. Yuanyang, Z.; Bin, T.; Guangbin, L.; Liansheng, L.; Huaide, Y.; Wenhui, M.; Haiping, X. Experimental research on dynamic response of capacity control system in reciprocating compressor. Proc. Inst. Mech. Eng. Part C J. Mech. Eng. Sci. 2014, 228, 358-365. [CrossRef]

18. Tang, B.; Zhao, Y.; Li, L.; Wang, L.; Liu, G.; Yang, Q.; Meng, W. Dynamic characteristics of suction valves for reciprocating compressor with stepless capacity control system. Proc. Inst. Mech. Eng. Part C J. Mech. Eng. Sci. 2014, 228, 104-114. [CrossRef]

19. He, Z.; Jian, Z.; Wang, T.; Li, D.; Peng, X. Investigation on the variation of pressure in the cylinder of the refrigerator compressor based on fsi model. IOP Conf. Ser. Mater. Sci. Eng. 2017, 232, 012005. [CrossRef]

20. Lacerda, J.F.; Takemori, C.K. CFD Approach to Evaluate Heat Transfer in Reciprocating Compressors. In Proceedings of the International Compressor Engineering Conference, Purdue, 11-14 July 2016; Available online: https://docs.lib.purdue.edu/cgi/viewcontent.cgi?article=3486\&context=icec (accessed on 11 April 2020).

21. Bing, W.U.; Jiang, Z.N. The force analysis of reciprocating compressor valve using cfd. Compress. Technol. 2011, 4, 24-26.

22. Mi, X.; Li, Q.; Wang, F.; Zhao, X. Flow field simulation of reciprocating compressor based on dynamic mesh technology. In Proceedings of the 2017 IEEE 21st International Conference on Computer Supported Cooperative Work in Design (CSCWD), Wellington, New Zealand, 26-28 April 2017. 